\title{
Assessment of the Melody valve in the mitral position in young children by echocardiography
}

Lindsay R. Freud, MD, ${ }^{\mathrm{a}}$ Gerald R. Marx, MD, ${ }^{\mathrm{a}}$ Audrey C. Marshall, MD, ${ }^{\mathrm{a}}$ Wayne Tworetzky, MD, ${ }^{\mathrm{a}}$ and Sitaram M. Emani, MD ${ }^{\mathrm{b}}$

\section{ABSTRACT}

Objectives: Mitral valve replacement (MVR) in young children is limited by the lack of small prostheses. Our institution began performing MVR with modified, surgically placed, stented jugular vein grafts (Melody valve) in 2010. We sought to describe key echocardiographic features for pre- and postoperative assessment of this novel form of MVR.

Methods: The pre- and postoperative echocardiograms of 24 patients who underwent Melody MVR were reviewed. In addition to standard measurements, preoperative potential measurements of the mitral annulus were performed whereby dimensions were estimated for Melody sizing. A ratio of the narrowest subaortic region in systole to the actual mitral valve dimension (SubA:MV) was assessed for risk of postoperative left ventricular outflow tract obstruction (LVOTO).

Results: Melody MVR was performed at a median of 8.5 months $(5.6 \mathrm{~kg}$ ) for stenosis (5), regurgitation (3), and mixed disease (16). Preoperatively, actual mitral z scores measured hypoplastic (median -3.1 for the lateral [lat] dimension; -2.1 for the anteroposterior [AP] dimension). The potential measurements often had normal $\mathrm{z}$ scores with fair correlation with intraoperative Melody dilation ( $\rho=0.51$ and 0.50 for lat and AP dimensions, respectively, both $P=.01$ ). A preoperative SubA:MV $<0.5$ was associated with postoperative LVOTO, which occurred in 4 patients. Postoperatively, mitral gradients substantially improved, with low values relative to the effective orifice area of the Melody valve. No patients had significant regurgitation or perivalvar leak.

Conclusions: Preoperative echocardiographic measurements may help guide intraoperative sizing for Melody MVR and identify patients at risk for postoperative LVOTO. Acute postoperative hemodynamic results were favorable; however, ongoing assessment is warranted. ( $\mathrm{J}$ Thorac Cardiovasc Surg 2017;153:153-60)

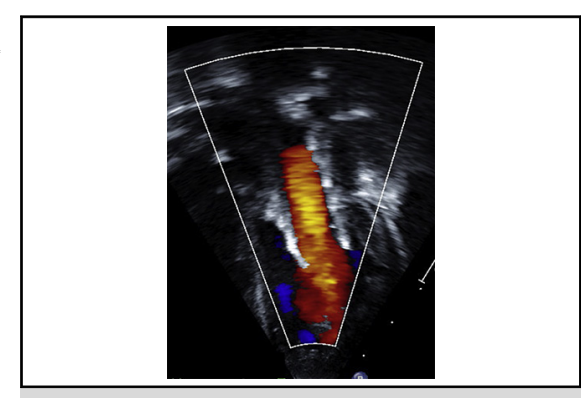

Echocardiographic image of the Melody valve in the mitral position in a young child.

\section{Central Message}

Preoperative echocardiographic measurements may help guide intraoperative placement of the Melody valve in the mitral position in young children.

\section{Perspective}

Surgical placement of the Melody valve in the mitral position is a new, evolving technique for mitral valve replacement in young children. We define preoperative echocardiographic measurements that may inform intraoperative sizing and implantation. In addition, we provide a comprehensive description of the echocardiographic features of the Melody valve in the mitral position postoperatively.

See Editorial Commentary page 161.

See Editorial page 151.
Valve replacement in infants and young children is complicated by the lack of adequately sized prostheses and the need for subsequent replacements over time

\footnotetext{
From the Departments of acCardiology and ${ }^{\mathrm{b} C a r d i a c}$ Surgery, Boston Children's Hospital, Harvard Medical School, Boston, Mass.

Dr Freud was supported by the National Institutes of Health (T32-HL007572) and the Kenrose Kitchen Foundation.

L. Freud is now at Columbia University Medical Center.

Received for publication Feb 22, 2016; revisions received June 24, 2016; accepted for publication July 1, 2016; available ahead of print Aug 11, 2016.

Address for reprints: Lindsay R. Freud, MD, Morgan Stanley Children's Hospital of New York-Presbyterian, 3959 Broadway, CHN2, New York, NY 10032 (E-mail: 1rf2136@columbia.edu).

$0022-5223 / \$ 36.00$

Copyright (C) 2016 by The American Association for Thoracic Surgery

http://dx.doi.org/10.1016/j.jtcvs.2016.07.017
}

due to somatic growth. Mitral valve replacement (MVR), in particular, has proven to be challenging in this population with relatively high rates of reintervention and mortality. ${ }^{1-9}$ A stent-mounted, valved, bovine jugular vein graft (Melody valve, Medtronic, Inc, Minneapolis, Minn), which is approved for transcatheter pulmonary valve replacement, was adapted for implantation into the mitral position in

Scanning this QR code will take you to supplemental videos and figure for this article.

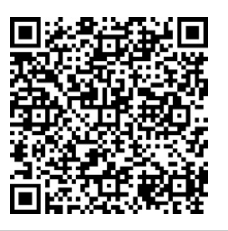




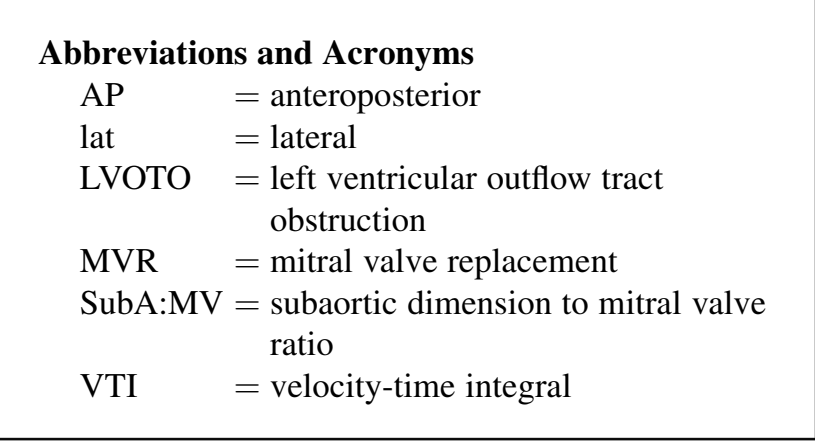

$2010 .^{10,11}$ This technique permits tailoring of valve size to small annular dimensions $(<15 \mathrm{~mm})$ at the time of implantation, as well as the opportunity for later expansion in the catheterization laboratory to accommodate somatic growth.

The surgical techniques and short-term outcomes of Melody MVR have been previously described. ${ }^{11}$ Although the early results are encouraging, postoperative complications, such as left ventricular outflow tract obstruction (LVOTO), have been reported. Sizing of the Melody valve at the time of implantation is currently determined by intraoperative inspection. We hypothesized that the preoperative echocardiogram would be useful to determine appropriate sizing for Melody valve expansion and to help predict which patients may be at risk for LVOTO. Echocardiographic characteristics of the Melody valve after implantation in the mitral position have also not been described. Therefore, the aims of this exploratory study were to (1) define preoperative echocardiographic measurements that may inform intraoperative sizing of the Melody valve and the risk for postoperative LVOTO; and (2) provide a comprehensive

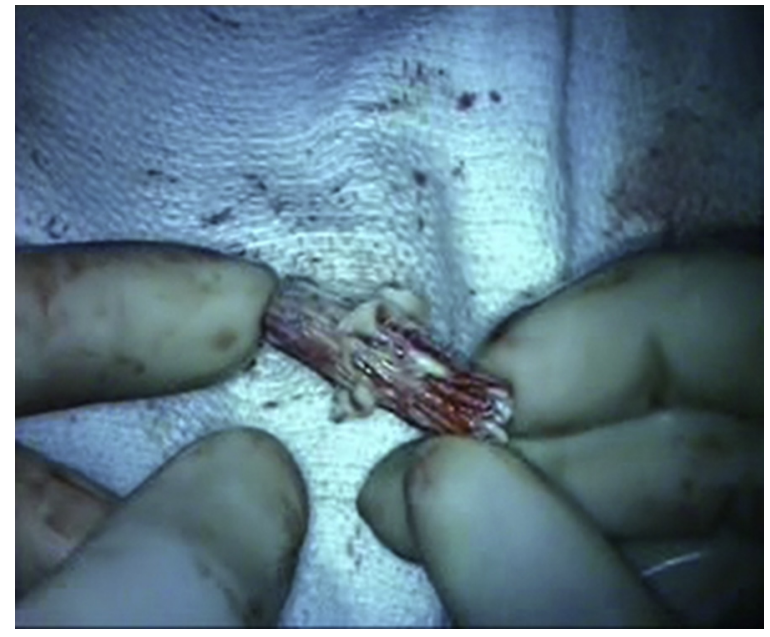

VIDEO 1. Intraoperative insertion of the modified Melody valve in the mitral position in a young patient. Video available at http://www. jtcvsonline.org/article/S0022-5223(16)30828-5/addons.

description of early echocardiographic features after Melody MVR.

\section{METHODS}

Patients who underwent Melody MVR from March 2010 to March 2015 at Boston Children's Hospital were retrospectively reviewed. The operative procedure has been described previously. ${ }^{10,11}$ Briefly, the Melody valve is modified with the addition of a sewing cuff and resection of stent crowns. Right atriotomy is most often performed, and the compressed, modified valve is placed in the mitral annulus via a transseptal approach. Mitral annulus upsizing, as previously reported by our group, ${ }^{12}$ is not performed because the Melody valve may be dilated over time. The ventricular end of the valve stent is fixed to the posteroinferior left ventricular wall to prevent LVOTO. The Melody valve is anchored to the mitral annulus and expanded to the desired diameter using catheterization balloons (see Video 1). Fenestrated closure of the interatrial septum is performed.
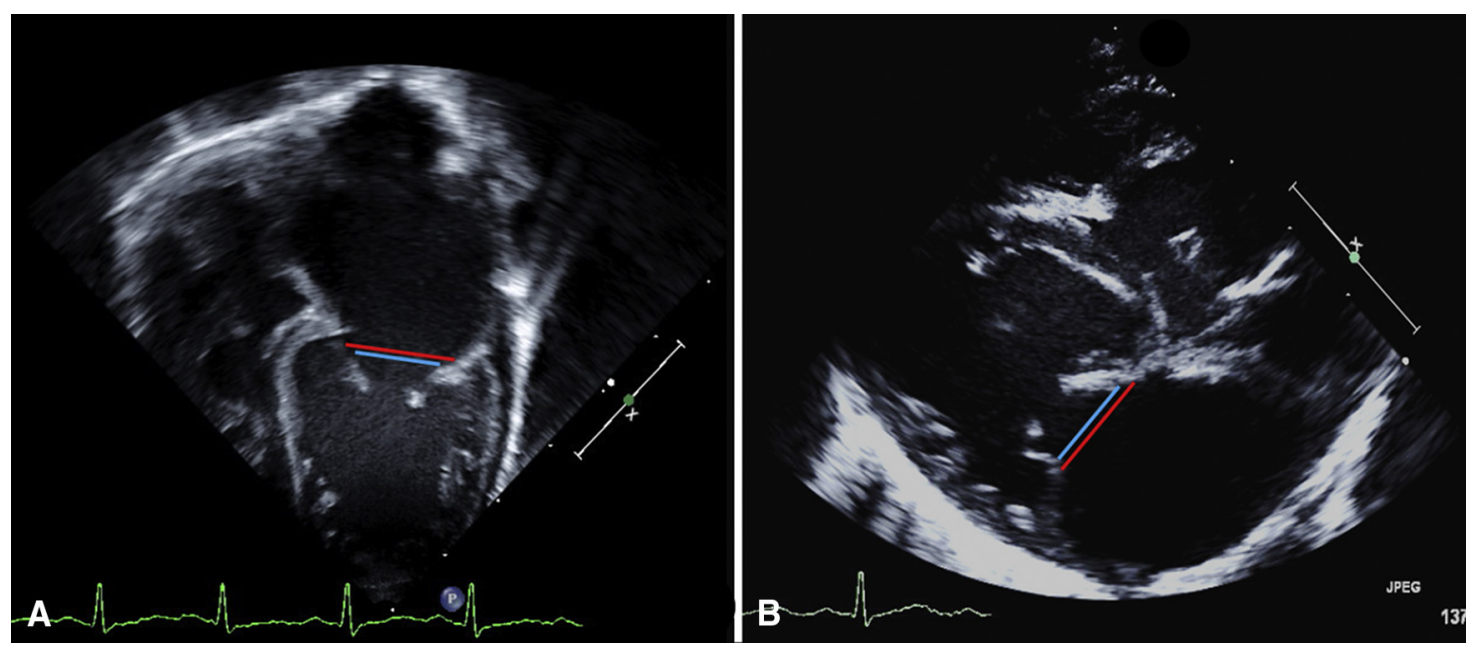

FIGURE 1. Illustration of the actual (blue) and potential (red) mitral valve measurements in the (A) lateral and (B) anteroposterior dimensions at the level of the annulus. 
TABLE 1. Preoperative patient characteristics $(n=24)$

\begin{tabular}{|c|c|}
\hline Male & $14(58)$ \\
\hline Age (mo) & $8.5(0.8-38.0)$ \\
\hline Weight $(\mathrm{kg})$ & $5.6(3.2-14.7)$ \\
\hline Body surface area $\left(\mathrm{m}^{2}\right)$ & $0.3(0.2-0.6)$ \\
\hline Genetic syndrome* & $4(17)$ \\
\hline \multicolumn{2}{|l|}{ Native anatomy } \\
\hline Isolated congenital mitral valve abnormality & $4(17)$ \\
\hline Additional left heart obstructive lesions & $12(50)$ \\
\hline Atrioventricular canal $\dagger$ & $8(33)$ \\
\hline \multicolumn{2}{|l|}{ Indication for Melody mitral valve replacement } \\
\hline Stenosis & $5(21)$ \\
\hline Regurgitation & $3(12)$ \\
\hline Mixed disease & $16(67)$ \\
\hline \multicolumn{2}{|l|}{ Previous mitral valve intervention } \\
\hline Catheter-based balloon dilation & $6(25)$ \\
\hline $\begin{array}{l}\text { Surgical mitral valve repair (including } \\
\text { atrioventricular canal repair) }\end{array}$ & $21(88)$ \\
\hline Mitral valve replacement $\ddagger$ & $2(8)$ \\
\hline Age at first previous mitral valve intervention (mo) & $4.0(0.5-24.0)$ \\
\hline \multicolumn{2}{|l|}{ Other previous interventions } \\
\hline Cather-based balloon dilation of aortic valve & $5(21)$ \\
\hline Coarctation repair/arch reconstruction & $7(29)$ \\
\hline Staged univentricular palliation $\S$ & $2(8)$ \\
\hline
\end{tabular}

Our study was approved by the Institutional Review Board, with a waiver of informed consent. We included patients with any indication for MVR, including those with previous mitral valve repair or replacement or previous staged univentricular palliation with subsequent conversion to a biventricular circulation. Patients with abnormal situs and discordant atrioventricular and/or ventriculoarterial connections (eg, complex heterotaxy) were excluded.

Preoperative demographic and clinical variables were collected, including cardiac diagnosis, associated genetic syndromes, previous catheterizations and/or surgeries, and the indication for MVR. The complete preoperative transthoracic echocardiogram obtained before Melody MVR was reviewed, with particular attention to the following indices: left atrial and ventricular dimensions; mitral and aortic dimensions and z scores; degree of LVOTO; right ventricular pressure as estimated from the tricuspid regurgitation jet velocity (plus $5 \mathrm{~mm} \mathrm{Hg}$ for the estimated right atrial pressure); and right ventricular dysfunction, dilation, and hypertrophy as assessed qualitatively.

With regard to the mitral valve annulus, actual measurements were performed at the hingepoints of the valve leaflets, per standard convention, in the lateral (lat) and anteroposterior (AP) planes from the apical 4-chamber and parasternal long-axis views, respectively. We performed novel potential measurements to estimate the maximum intraoperative expansion of the Melody valve in the same lat and AP planes using two-dimensional echocardiography. As demonstrated in Figure 1, a line was drawn at the level of the annulus, which typically extended beyond the actual valve hingepoints, to estimate the degree to which the Melody valve could be reasonably expanded without impinging on nearby structures. Such structures, which were systematically identified, included the circumflex coronary artery, the presumptive location of the atrioventricular node, and the aortic valve annulus and left ventricular outflow tract. All measurements were agreed upon by 2 echocardiographers
TABLE 2. Echocardiographic measurements before placement of the Melody valve in the mitral position $(n=24)$

\begin{tabular}{|c|c|c|}
\hline & Measurement & z Score \\
\hline \multicolumn{3}{|l|}{ Anatomic dimensions } \\
\hline $\begin{array}{l}\text { Actual lateral mitral } \\
\text { dimension }(\mathrm{cm})\end{array}$ & $0.8(0.5-1.8)$ & $-3.1(-5.9$ to 1.5$)$ \\
\hline $\begin{array}{l}\text { Potential lateral mitral } \\
\text { dimension }(\mathrm{cm})\end{array}$ & $1.4(1.0-1.8)$ & $1.1(-2.2$ to 4.2$)$ \\
\hline $\begin{array}{l}\text { Actual anteroposterior mitral } \\
\text { dimension }(\mathrm{cm})\end{array}$ & $0.9(0.4-1.5)$ & $-2.1(-4.9$ to 1.4$)$ \\
\hline $\begin{array}{l}\text { Potential anteroposterior mitral } \\
\text { dimension }(\mathrm{cm})\end{array}$ & $1.4(0.9-2.3)$ & $1.8(-1.3$ to 4.7$)$ \\
\hline Actual mitral valve area $\left(\mathrm{cm}^{2}\right)$ & $0.5(0.2-3.4)$ & $-2.1(-3.4$ to 3.6$)$ \\
\hline $\begin{array}{l}\text { Left atrial dimension } \\
\quad(\text { supero-inferior plane, } \mathrm{cm})\end{array}$ & $3.3(2.5-4.4)$ & - \\
\hline $\begin{array}{l}\text { Left ventricular length, } \\
\text { diastole }(\mathrm{cm})\end{array}$ & $3.5(2.5-4.4)$ & $0.1(-3.2$ to 3.8$)$ \\
\hline $\begin{array}{l}\text { Left ventricular volume, } \\
\text { diastole }(\mathrm{mL})\end{array}$ & $14.2(4.8-42.5)$ & $0.8(-4.4$ to 6.9$)$ \\
\hline $\begin{array}{l}\text { Left ventricular volume, } \\
\text { systole }(\mathrm{mL})\end{array}$ & $5.8(1.9-20.1)$ & $0.8(-3.2$ to 6.9$)$ \\
\hline $\begin{array}{l}\text { Subaortic dimension in } \\
\text { systole }(\mathrm{cm})\end{array}$ & $0.6(0.4-1.3)$ & - \\
\hline SubA:MV & $0.7(0.3-1.4)$ & - \\
\hline Aortic valve $(\mathrm{cm})$ & $0.7(0.4-1.2)$ & $-2.3(-4.2$ to 4.8$)$ \\
\hline \multicolumn{3}{|l|}{ Functional parameters } \\
\hline Mean mitral gradient $(\mathrm{mm} \mathrm{Hg})$ & $12(3-22)$ & - \\
\hline Mitral regurgitation & & - \\
\hline Mild or less & $5(21)$ & \\
\hline Moderate & $11(46)$ & \\
\hline Severe & $8(33)$ & \\
\hline $\begin{array}{l}\text { Left ventricular ejection } \\
\text { fraction }(\%)\end{array}$ & $60(33-83)$ & - \\
\hline $\begin{array}{l}\text { Right ventricular pressure } \\
\quad \geq 1 / 2 \text { systemic }\end{array}$ & $22(92)$ & - \\
\hline Right ventricular dysfunction & & - \\
\hline Mild & $12(50)$ & \\
\hline Moderate to severe & $4(17)$ & \\
\hline Right ventricular dilation & & - \\
\hline Mild & $11(46)$ & \\
\hline Moderate to severe & $6(25)$ & \\
\hline Right ventricular hypertrophy & & - \\
\hline Mild & $10(42)$ & \\
\hline Moderate to severe & $8(33)$ & \\
\hline
\end{tabular}

Values are expressed as frequency (\%) or median (range). SubA:MV, The ratio of the smallest subaortic dimension in systole to the actual anteroposterior mitral measurement in diastole as measured from the parasternal long-axis view.

who were blinded to the clinical outcome. In addition, because LVOTO potentially occurs in the subaortic region with expansion of the valve, we devised a ratio consisting of the narrowest subaortic region in systole, as measured from the parasternal long-axis view, to the actual AP mitral annulus dimension (subaortic dimension to mitral valve ratio [SubA:MV]), also from the parasternal long-axis view.

Postoperatively, the last complete transthoracic echocardiogram before discharge was reviewed. There was 1 patient in whom dilation of the Melody valve was performed in the catheterization laboratory before discharge. This patient's echocardiogram before the intervention, as 

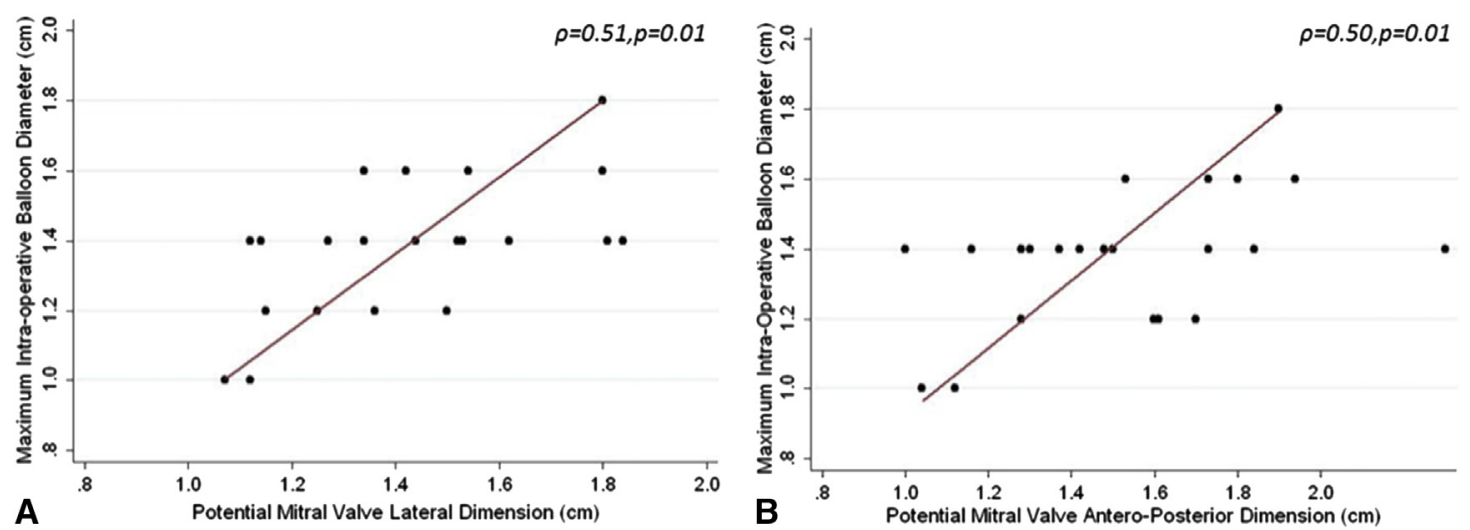

FIGURE 2. Correlation between the preoperative potential mitral valve (A) lateral and (B) anteroposterior dimensions and the maximum balloon dilation of the Melody valve intraoperatively.

opposed to before discharge, was included. In addition to re-examining the indices described previously, the inner diameter of the Melody valve at the native annulus was measured. The length of the stent in the left atrium and the total length of the stent were also noted from an apical 4-chamber view. Peak and mean gradients were obtained by continuous-wave and pulsewave Doppler imaging at various points along the Melody MVR. Pressure half-times were attempted but were only able to be performed in a small number of patients because of fusion of the early (E) and atrial (A) waves. The velocity-time integrals (VTI) across the mitral and aortic valves were measured, which, in conjunction with the cross-sectional area of the aortic valve derived from the annular measurement, were used for estimation of the effective mitral valve orifice area by the continuity equation (effective mitral valve orifice area $=$ [cross-sectional area of aortic valve $\times$ VTI of aortic valve]/VTI of mitral valve). The indexed effective orifice area, which is the effective orifice area adjusted for body surface area $\left(\mathrm{m}^{2}\right)$, was also determined.

LVOTO was defined as a peak gradient of $\geq 20 \mathrm{~mm} \mathrm{Hg}$. Because the continuity equation does not apply to patients with LVOTO, we excluded such patients from the effective orifice area calculations. Careful inspection was performed for the presence of perivalvar leak or valve instability, pulmonary vein obstruction, or regional wall motion abnormalities suggestive of impingement on the circumflex coronary artery. Patients were followed up until April 2015. Removal of the Melody valve, heart transplant, or death were noted.

Values are presented as frequency (\%) and median (range) because of the sample size. For postoperative measurements across the Melody valve, the means \pm standard deviation are also reported in accordance with other published values for evaluation of mitral valve prostheses, ${ }^{13}$ where feasible, to facilitate comparisons. Correlation between continuous variables was assessed with the Spearman coefficient $(\rho)$. Bland-Altman plots were used to demonstrate agreement between measurements. Two-sided $P$ values $<.05$ were considered statistically significant.

\section{RESULTS}

Twenty-six patients underwent Melody MVR at our institution over the study period. Two patients were excluded due to complex heterotaxy. The preoperative characteristics of the 24 patients who met inclusion criteria are given in Table 1. Briefly, Melody MVR was performed at a median age of 8.5 months and a median weight of $5.6 \mathrm{~kg}$ for stenosis $(n=5)$, regurgitation $(n=3)$, or mixed disease $(\mathrm{n}=16)$. All but 1 patient had previous catheter-based or surgical mitral valve intervention.
The preoperative echocardiographic measurements are listed in Table 2. The actual mitral valve measurements frequently measured hypoplastic, whereas the larger potential measurements often allowed for normalization of the annulus.

Intraoperatively, the Melody valve was maximally dilated to a median of $1.4 \mathrm{~cm}(1.0-1.8 \mathrm{~cm})$. Twelve patients $(50 \%)$ had balloon dilations of $1.4 \mathrm{~cm}$. The potential mitral valve annulus in the lat and AP planes had fair correlation with the maximum intraoperative balloon diameter ( $\rho=0.51$ and 0.50 , both $P=.01$; Figure 2). Bland-Altman plots between the echocardiographic measurements and the maximum balloon diameter also demonstrated reasonable agreement (Figure E1).

Postoperative echocardiograms before hospital discharge (or intervention) were performed at a median of 10 days (5-55 days) following surgery. Figure 3 and Video 2 demonstrate the postoperative appearance of the Melody valve in the mitral position. The mean mitral gradients improved by $7 \mathrm{~mm} \mathrm{Hg}(0-16 \mathrm{~mm} \mathrm{Hg})$, and no patients had more than trivial residual regurgitation. For patients with measurable tricuspid regurgitation jets postoperatively (17/24), right ventricular pressure decreased by a median of $18 \mathrm{~mm} \mathrm{Hg}$. Based on this measurement or the septal contour in the remaining 7 patients, the right ventricular pressure was less than half systemic in $75 \%$ of patients by the time of discharge.

Table 3 lists the peak and mean gradients, peak velocity, and effective orifice area of the Melody valve in the mitral position based on the maximum intraoperative dilation. The reported measurements were obtained by continuous-wave Doppler imaging, which consistently yielded higher results than pulse-wave Doppler imaging at various points along the Melody valve. The gradients were higher across Melody valves dilated to smaller diameters, as would be expected, with the exception of the subgroup dilated to $1.6 \mathrm{~cm}$. This subgroup $(\mathrm{n}=4)$ consisted of 2 particularly challenging patients, including a patient 

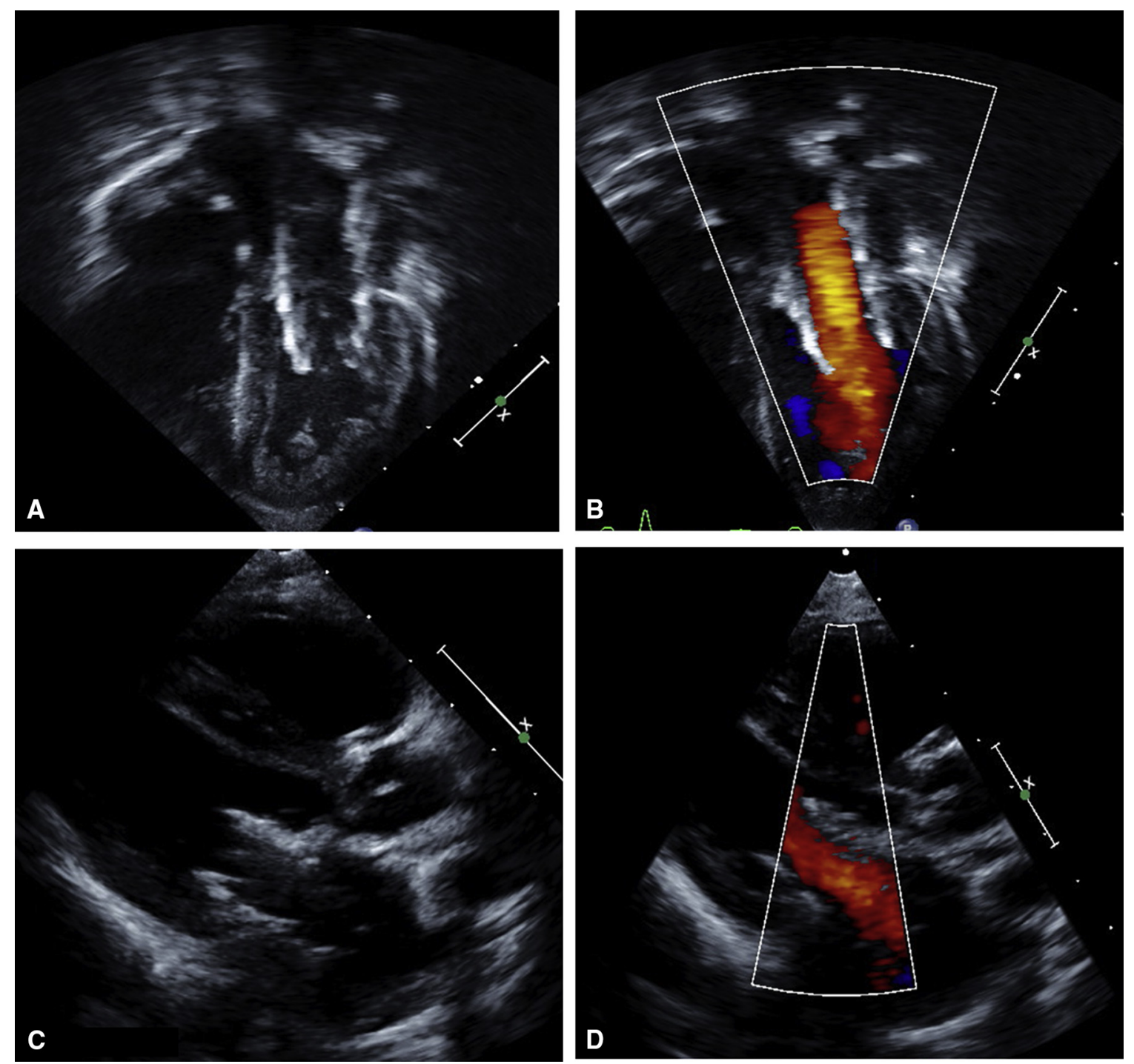

FIGURE 3. Examples of the Melody valve in the mitral position postoperatively by two-dimensional and color flow Doppler imaging in the (A, B) apical 4-chamber and (C, D) parasternal long-axis views.

who underwent previous staged univentricular palliation and required dilation of the Melody valve in the catheterization laboratory before hospital discharge and another who had preoperative LVOTO and required myectomy and resection of a subaortic membrane at the time of Melody MVR.

A total of 3 patients had preoperative LVOTO with peak and mean gradients of $31 \mathrm{~mm} \mathrm{Hg}(14-60 \mathrm{~mm} \mathrm{Hg})$ and $19 \mathrm{~mm} \mathrm{Hg}(7-34 \mathrm{~mm} \mathrm{Hg})$, respectively. All these patients had concomitant surgery to relieve the obstruction at the time of Melody valve implantation. Following Melody MVR, 4 patients had LVOTO with peak and mean gradients of $28 \mathrm{~mm} \mathrm{Hg} \mathrm{(23-35} \mathrm{mm} \mathrm{Hg)} \mathrm{and} 15 \mathrm{~mm} \mathrm{Hg}(11-16 \mathrm{~mm}$ $\mathrm{Hg}$ ), respectively. The obstruction occurred predominantly in the subaortic region. One had an unbalanced right-dominant atrioventricular canal defect, and 2 had preoperative LVOTO. Two patients had SubA:MV $<0.5$. Among patients without LVOTO, 90\% (18/20) had a SubA:MV $\geq 0.5$.

Three patients had mild perivalvar leaks without readily identifiable risk factors. The patient with the previous staged univentricular palliation that required early reintervention had both LVOTO and a mild perivalvar leak. Figure 4 depicts examples of LVOTO and perivalvar leak.

The internal diameter of the Melody valve measured $0.4 \mathrm{~cm}(0.1-0.8 \mathrm{~cm})$ less than the maximum intraoperative balloon diameter. The median length of the stent in the left atrium was $1.6 \mathrm{~cm}(0.9-2.3 \mathrm{~cm})$, which was a median of $56 \%(28 \%-68 \%)$ of the total stent length. The proportion of the stent in the left atrium versus left ventricle was not clearly associated with a risk for LVOTO or perivalvar leak. No patients had pulmonary vein obstruction 


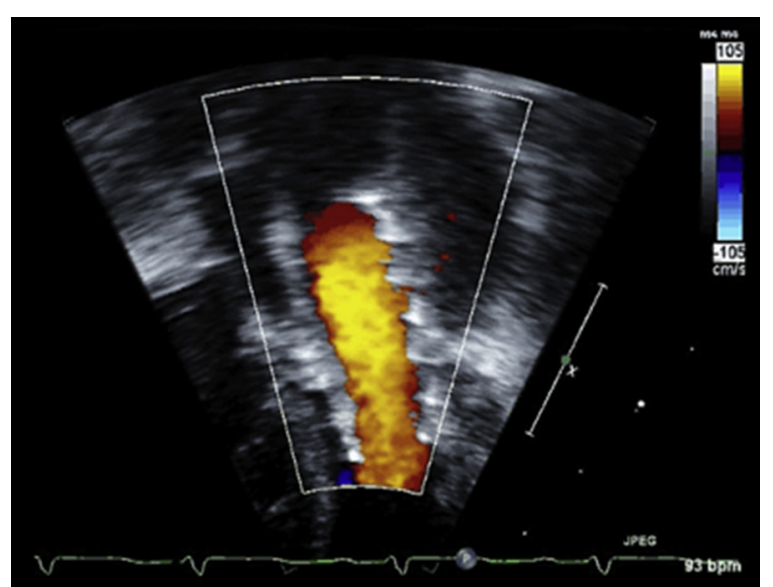

VIDEO 2. Transthoracic echocardiogram demonstrating a wellfunctioning Melody valve in the mitral position from an apical 4-chamber view. Video available at: http://www.jtcvsonline.org/article/S00225223(16)30828-5/addons.

or regional wall motion abnormalities suggestive of impingement on the circumflex coronary artery. One patient developed complete heart block requiring pacemaker implantation 12 days after Melody MVR. There were no acute episodes of endocarditis or thromboembolic complications.

The median age at latest follow-up was 31.2 months (3.556.0 months), which was 14.0 months (0.2-42.0 months) from the time of Melody MVR. One patient died from sepsis 10 months after Melody MVR, and another patient was successfully transplanted 2 months after Melody MVR because of persistent left ventricular dysfunction. Four patients had their Melody valves replaced at a median of 15.2 months (5.5-24.5 months) after surgery with tissue mitral valve prostheses, which is our institutional preference. The Melody valve was replaced for late endocarditis and perforation of the Melody valve leaflets $(n=1)$, possible Melody valve stent fracture $(\mathrm{n}=1)$, worsening perivalvar leak not responsive to catheter intervention $(\mathrm{n}=1)$, and elective valve upsizing at the time of a concomitant Ross procedure $(\mathrm{n}=1)$.

\section{DISCUSSION}

Placement of the Melody valve in the mitral position is an emerging option for infants and young children with small annuli. ${ }^{10,11}$ This report describes the use of the preoperative transthoracic echocardiogram to provide parameters for surgical implantation of the Melody valve. The preoperative SubA:MV ratio may help assess the risk for postoperative LVOTO, which is an important complication. This report also provides the most comprehensive description to date of the echocardiographic features of the Melody valve in the mitral position after implantation.

In this cohort of infants and young children with mitral valve disease, the actual mitral $\mathrm{z}$ scores were frequently hypoplastic preoperatively. The potential z scores, however, were often closer to 0 , which would permit a normal-sized annulus for the body surface area. The potential measurements from the preoperative echocardiogram correlated fairly well with the intraoperative balloon dilation performed by the surgeon on visual inspection and, therefore, may be used as a guide for intraoperative sizing. Importantly, the sizing technique used in this series was safe for most patients: none sustained coronary artery damage and only 1 developed complete heart block requiring pacemaker implantation. This incidence of complete heart block was lower than that previously reported with mitral annulus upsizing in children from our institution ${ }^{12}$ and underscores the potential benefit of the Melody valve, which allows for serial dilation over time.

With regard to the risk for postoperative LVOTO, we found that a preoperative SubA:MV ratio $<0.5$ may be a useful parameter. In addition, the presence of preoperative LVOTO was a risk factor, as would be expected. Interestingly, only 1 of 8 patients with an atrioventricular canal defect developed LVOTO, and this patient had an unbalanced right-dominant type with previous univentricular palliation. For patients with a SubA:MV ratio $<0.5$, preoperative LVOTO, or any other anatomic risk factor, eg, atrioventricular canal defect, consideration should be given to alternative or adjunctive measures to prevent LVOTO, such as more aggressive resection of stent material, atrial displacement of the valve, or less aggressive distal expansion of the valve. In some patients, as right ventricular pressure decreases as a result of relief of mitral valve disease, LVOTO may improve with anterior displacement of the interventricular septum.

The Melody valve was successful in reducing right ventricular pressure and, importantly, no patients had significant residual mitral regurgitation. This finding has been shown to correlate with better outcomes after mitral valve surgery in children. ${ }^{14}$ To facilitate ongoing assessment of Melody valve function, we outlined baseline gradients, velocities, and effective orifice areas for patients with different maximum balloon diameters shortly after implantation. Compared with published normative values for other prosthetic valves in the mitral position, ${ }^{13}$ the Melody valve had low gradients relative to the effective orifice area. The reasons why the Melody valve measured smaller than the intraoperative dilation are unclear but may be related to placement of the valve in a native, nonconduit position, intraoperative distention of flaccid tissues, and/or anatomic and physiologic alterations that occur with chest closure.

Although the Melody valve may measure up to $2.5 \mathrm{~cm}$ in length when unexpanded, the combined left atrial and ventricular dimensions were more than adequate. For all 
TABLE 3. Postoperative measurements across the Melody valve in the mitral position by maximum intraoperative balloon diameter $(\mathbf{n}=23) *$

\begin{tabular}{|c|c|c|c|}
\hline$\underline{\text { Balloon diameter }}$ & Measurement & Median (range) & Mean \pm SD \\
\hline \multirow[t]{5}{*}{$1.0 \mathrm{~cm}(\mathrm{n}=2)$} & Peak gradient (mm Hg) & $13.0(10.0-16.0)$ & $\mathrm{n} / \mathrm{a}$ \\
\hline & Mean gradient (mm Hg) & $5.0(4.0-6.0)$ & $\mathrm{n} / \mathrm{a}$ \\
\hline & Peak velocity $(\mathrm{m} / \mathrm{s})$ & $1.8(1.6-2.1)$ & $\mathrm{n} / \mathrm{a}$ \\
\hline & Effective orifice area $\left(\mathrm{cm}^{2}\right) \dagger$ & $0.20(0.18-0.23)$ & $\mathrm{n} / \mathrm{a}$ \\
\hline & Indexed effective orifice area $\left(\mathrm{cm}^{2} /\right.$ body surface area) & $0.79(0.78-0.79)$ & $\mathrm{n} / \mathrm{a}$ \\
\hline \multirow[t]{5}{*}{$1.2 \mathrm{~cm}(\mathrm{n}=4)$} & Peak gradient (mm Hg) & $9.5(3.0-16.0)$ & $9.5 \pm 5.3$ \\
\hline & Mean gradient (mm Hg) & $4.5(1.0-8.0)$ & $4.5 \pm 2.9$ \\
\hline & Peak velocity (m/s) & $1.4(0.9-1.6)$ & $1.3 \pm 0.3$ \\
\hline & Effective orifice area $\left(\mathrm{cm}^{2}\right)$ & $0.34(0.22-0.69)$ & $0.42 \pm 0.24$ \\
\hline & Indexed effective orifice area $\left(\mathrm{cm}^{2} /\right.$ body surface area) & $1.55(0.86-2.31)$ & $1.57 \pm 0.73$ \\
\hline \multirow[t]{5}{*}{$1.4 \mathrm{~cm}(\mathrm{n}=12)$} & Peak gradient (mm Hg) & $9.5(3.0-11.0)$ & $8.0 \pm 3.0$ \\
\hline & Mean gradient (mm Hg) & $3.0(2.0-6.0)$ & $3.4 \pm 1.2$ \\
\hline & Peak velocity $(\mathrm{m} / \mathrm{s})$ & $1.5(0.8-1.6)$ & $1.4 \pm 0.3$ \\
\hline & Effective orifice area $\left(\mathrm{cm}^{2}\right)$ & $0.54(0.35-0.77)$ & $0.54 \pm 0.15$ \\
\hline & Indexed effective orifice area $\left(\mathrm{cm}^{2} /\right.$ body surface area) & $1.45(0.92-2.54)$ & $1.45 \pm 0.43$ \\
\hline \multirow[t]{5}{*}{$1.6 \mathrm{~cm}(\mathrm{n}=4)$} & Peak gradient (mm Hg) & $14.5(6.0-26.0)$ & $15.0 \pm 8.5$ \\
\hline & Mean gradient (mm Hg) & $8.0(3.0-13.0)$ & $8.0 \pm 4.8$ \\
\hline & Peak velocity $(\mathrm{m} / \mathrm{s})$ & $1.8(1.3-2.5)$ & $1.9 \pm 0.5$ \\
\hline & Effective orifice area $\left(\mathrm{cm}^{2}\right) \dagger$ & $1.16(0.62-1.7)$ & $\mathrm{n} / \mathrm{a}$ \\
\hline & Indexed effective orifice area $\left(\mathrm{cm}^{2} /\right.$ body surface area) & $2.77(1.19-4.36)$ & $\mathrm{n} / \mathrm{a}$ \\
\hline \multirow[t]{5}{*}{$1.8 \mathrm{~cm}(\mathrm{n}=1)$} & Peak gradient (mm Hg) & 7.0 & $\mathrm{n} / \mathrm{a}$ \\
\hline & Mean gradient (mm Hg) & 3.0 & $\mathrm{n} / \mathrm{a}$ \\
\hline & Peak velocity $(\mathrm{m} / \mathrm{s})$ & 1.3 & $\mathrm{n} / \mathrm{a}$ \\
\hline & Effective orifice area $\left(\mathrm{cm}^{2}\right)$ & $\mathrm{n} / \mathrm{a}$ & $\mathrm{n} / \mathrm{a}$ \\
\hline & Indexed effective orifice area $\left(\mathrm{cm}^{2} /\right.$ body surface area) & $\mathrm{n} / \mathrm{a}$ & $\mathrm{n} / \mathrm{a}$ \\
\hline
\end{tabular}

Values are presented as median (range) and mean \pm SD in accordance with other published values for mitral valve prostheses. ${ }^{13}$ Mean \pm SD was not reported if the subgroup was too small. For the final subgroup $(\mathrm{n}=1)$, the absolute values are presented. $S D$, Standard deviation; $n / a$, not applicable. *One patient was excluded due to creation of a funnel-shape with the Melody valve, with maximum balloon diameters ranging from 0.9 to $1.2 \mathrm{~cm}$ along the length of the stent. $\dagger$ Four patients with left ventricular outflow tract obstruction (1 patient in the $1.2 \mathrm{~cm}$ subgroup, 2 in the $1.6 \mathrm{~cm}$ subgroup, and 1 in the $1.8 \mathrm{~cm}$ subgroup) were excluded from calculation of effective orifice area.

the patients in our series, the left atrial or left ventricular length alone was $\geq 2.5 \mathrm{~cm}$. For select cases with more hypoplastic left ventricles, the Melody valve was placed with greater extension into the left atrium at the surgeons' discretion. This modification did not produce pulmonary vein obstruction, but it also did not seem to minimize LVOTO or perivalvar leak.
Our study was a retrospective exploratory analysis in a small group of patients undergoing a novel procedure and, therefore, has several limitations. Because of the small sample size, the heterogeneous population, and the limited number of acutely suboptimal outcomes, such as LVOTO, we were unable to quantitatively estimate risk and instead reported trends of outcomes. We
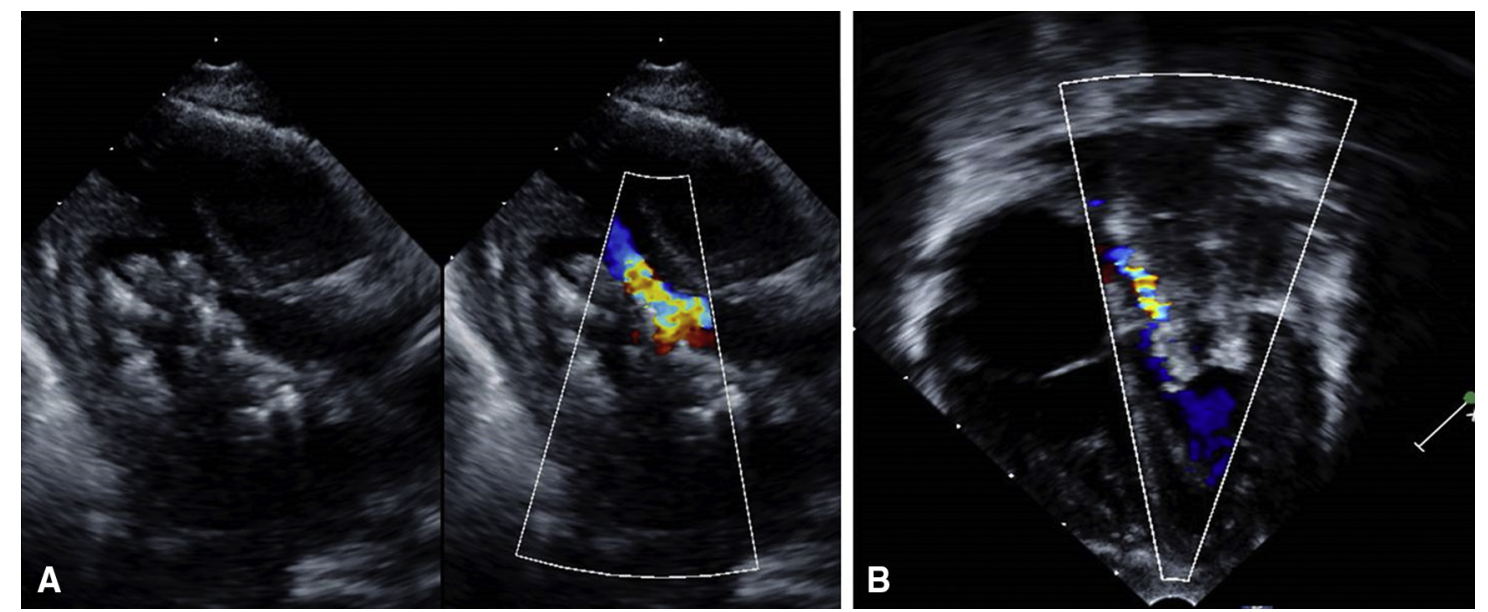

FIGURE 4. Examples of (A) left ventricular outflow tract obstruction as imaged from the parasternal long-axis view and (B) mild perivalvar leak as seen from the apical 4-chamber view. 
chose to use novel echocardiographic measurements that would be clinically useful for pediatric cardiologists and cardiac surgeons alike; namely, the potential measurements of the mitral valve annulus and the SubA:MV ratio. However, further experience with these measurements is necessary, with refinement and validation of the association between SubA:MV $<0.5$ and LVOTO in particular.

The measurements of the valve postoperatively can be challenging, partly due to artifact generated from the stent. The reported postoperative gradients and effective orifice areas are meant to serve as a general guide after Melody MVR but should be interpreted cautiously given the small sample sizes of each subgroup. Effective orifice areas are uncommonly calculated in the pediatric population, and three-dimensional imaging measurements may be a better option in the future. The echocardiographic findings need to be correlated with those obtained in the catheterization laboratory, particularly to elucidate which measurements may be most helpful for longer-term follow-up.

The potential benefits of the Melody valve in the mitral position are numerous. In addition to the ability to be tailored to annuli that are too small for currently available prostheses, the Melody valve may be expanded in the catheterization laboratory to accommodate somatic growth, may limit pannus formation, and avoids complications of anticoagulation in young children. ${ }^{15}$ As experience with Melody MVR evolves, we aimed to further our understanding of how to guide intraoperative placement and how to assess the valve postoperatively. Additional investigations are necessary with greater numbers of patients across institutions to refine patient selection and better elucidate the hemodynamics and echocardiographic assessment of this novel valve replacement strategy.

\section{CONCLUSIONS}

With the increasing use of the Melody valve in the mitral position in infants and young children, we sought to provide a framework for both pre- and early postoperative echocardiographic assessment. Potential mitral valve measurements may help guide intraoperative sizing, and the SubA:MV ratio may help identify patients at risk for postoperative LVOTO. Most patients in our series had acutely successful postoperative outcomes. Thus, we were able to outline baseline values for the Melody valve in the mitral position, which we hope will be able to guide ongoing assessment of valve function, including indications for catheter-based intervention. Validation of candidacy for Melody MVR and noninvasive assessment among larger series of patients will be necessary as greater experience with the Melody valve evolves.

\section{Conflicts of Interest Statement}

Dr Emani has filed a patent for an expandable valve through Boston Children's Hospital. All other authors have nothing to disclose with regard to commercial support.

\section{References}

1. Adatia I, Moore PM, Jonas RA, Colan SD, Lock JE, Keane JF. Clinical course and hemodynamic observations after supraannular mitral valve replacement in infants and children. J Am Coll Cardiol. 1997;29:1089-94.

2. Caldarone CA, Raghuveer G, Hills CB, Atkins DL, Burns TL, Behrendt DM, et al. Long-term survival after mitral valve replacement in children aged $<5$ years: a multi-institutional study. Circulation. 2001;104:I143-7.

3. Raghuveer G, Caldarone CA, Hills CB, Atkins DL, Belmont JM, Moller JH Predictors of prosthesis survival, growth, and functional status following mechanical mitral valve replacement in children aged $<5$ years, a multiinstitutional study. Circulation. 2003;108(Suppl 1):II174-9.

4. McElhinney DB, Sherwood MC, Keane JF, del Nido PJ, Almond CS, Lock JE Current management of severe congenital mitral stenosis: outcomes of transcatheter and surgical therapy in 108 infants and children. Circulation. 2005; 112:707-14.

5. Selamet Tierney ES, Pigula FA, Berul CI, Lock JE, del Nido PJ, McElhinney DB Mitral valve replacement in infants and children 5 years of age or younger: evolution in practice and outcome over three decades with a focus on supra-annular prosthesis implantation. J Thorac Cardiovasc Surg. 2008;136: 954-61. 961.e1-3.

6. Alsoufi B, Manlhiot C, McCrindle BW, Al-Halees Z, Sallehuddin A, Al-Oufi S, et al. Results after mitral valve replacement with mechanical prostheses in young children. J Thorac Cardiovasc Surg. 2010;139:1189-96. 1196.e1-2.

7. Alsoufi B, Manlhiot C, Al-Ahmadi M, McCrindle BW, Kalloghlian A, Siblini G, et al. Outcomes and associated risk factors for mitral valve replacement in children. Eur J Cardiothorac Surg. 2011;40:543-51.

8. Kanter KR, Kogon BE, Kirshbom PM. Supra-annular mitral valve replacement in children. Ann Thorac Surg. 2011;92:2221-7; discussion 2227-9.

9. Brown JW, Fiore AC, Ruzmetov M, Eltayeb O, Rodefeld MD, Turrentine MW. Evolution of mitral valve replacement in children: a 40-year experience. Ann Thorac Surg. 2012;93:626-33; discussion 633.

10. Abdullah I, Ramirez FB, McElhinney DB, Lock JE, del Nido PJ, Emani S Modification of a stented bovine jugular vein conduit (melody valve) for surgical mitral valve replacement. Ann Thorac Surg. 2012;94:e97-8.

11. Quinonez LG, Breitbart R, Tworetsky W, Lock JE, Marshall AC, Emani SM. Stented bovine jugular vein graft (Melody valve) for surgical mitral valve replacement in infants and children. J Thorac Cardiovasc Surg. 2014; 148:1443-9.

12. Myers PO, del Nido PJ, McElhinney DB, Khalpey Z, Lock JE, Baird CW Annulus upsizing for mitral valve re-replacement in children. J Thorac Cardiovasc Surg. 2013;146:347-51

13. Zoghbi WA, Chambers JB, Dumesnil JG, Foster E, Gottdiener JS, Grayburn PA, et al. Recommendations for evaluation of prosthetic valves with echocardiography and doppler ultrasound: a report From the American Society of Echocardiography's Guidelines and Standards Committee and the Task Force on Prosthetic Valves, developed in conjunction with the American College of Cardiology Cardiovascular Imaging Committee, Cardiac Imaging Committee of the American Heart Association, the European Association of Echocardiography, a registered branch of the European Society of Cardiology, the Japanese Society of Echocardiography and the Canadian Society of Echocardiography, endorsed by the American College of Cardiology Foundation, American Heart Association, European Association of Echocardiography, a registered branch of the European Society of Cardiology, the Japanese Society of Echocardiography, and Canadian Society of Echocardiography. J Am Soc Echocardiogr. 2009;22:975-1014. quiz 1082-4.

14. Alghamdi AA, Yanagawa B, Singh SK, Horton A, Al-Radi OO, Caldarone CA. Balancing stenosis and regurgitation during mitral valve surgery in pediatric patients. Ann Thorac Surg. 2011;92:680-4.

15. Moffett BS, Kim S, Bomgaars LR. Readmissions for warfarin-related bleeding in pediatric patients after hospital discharge. Pediatr Blood Cancer. 2013;60:1503-6.

Key Words: congenital heart disease, CHD, pediatric, mitral valve replacement, echocardiography 


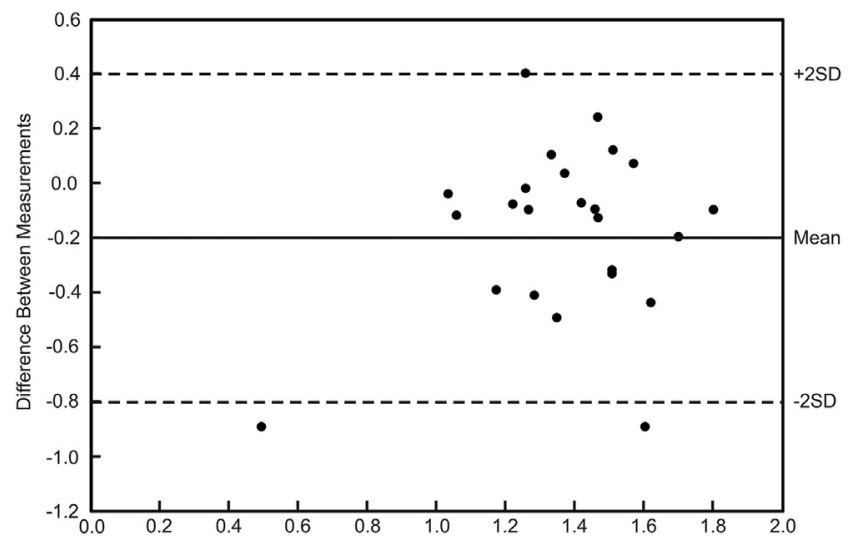

A

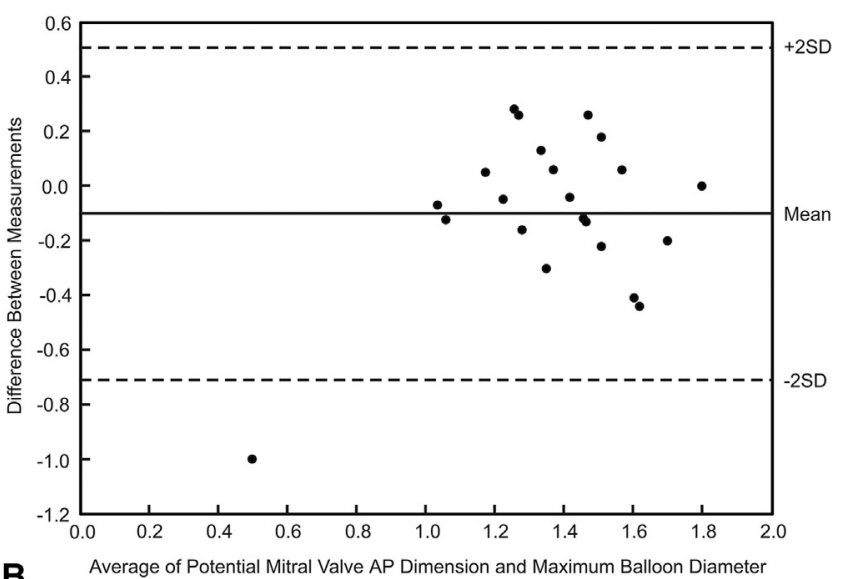

B

FIGURE E1. Bland-Altman plots demonstrating agreement between the (A) potential mitral valve lateral dimension and maximum balloon diameter and (B) potential mitral valve anteroposterior $(A P)$ dimension and maximum balloon diameter. The $\mathrm{x}$ axis represents the average of each pair of measurements, and the y axis represents the difference between each pair. The solid line depicts the mean difference, and the dashed lines depict 2 standard deviations ( $S D$ ) from the mean. 